\title{
PERANCANGAN SISTEM INFORMASI PENILAIAN KINERJA KARYAWAN BANK NAGARI CAB. LUBUK ALUNG BERBASIS JAVA
}

\author{
Nofriadiman $^{1}$, Deno Nazwarman ${ }^{2}$ \\ Program Studi Sistem Informasi, Sekolah Tinggi Teknologi Industri Padang \\ email: ${ }^{1}$ Nofriadiman@sttind.ac.id, ${ }^{2}$ d.nazwarman@gmail.com
}

Bank adalah suatu badan usaha yang bergerak di bidang keuangan atau jasa keuangan. Bank akan selalu berhubungan erat dengan masyarakat, untuk hal itu maka pelayanan menjadi penilaian suatu bank. Selama ini penilaian karyawan dilakukan secara manual menggunakan program aplikasi perkantoran. Masing masing data diolah secara manual dan tidak terintegrasi, seperti absensi kehadiran, disiplin, kenerja, prilaku, prestasi dan pencapaian target karyawan. Bank Nagari Cab. Lubuk Alung, hasil penilaian kerja yang sudah di sosialisasikan, perlu adanya standarisasi dan penilaian yang tepat, sehingga mewujudkan prestasi kerja yang memadai bagi tercapainya tujuan dan sasaran perusahaan. Diharapkan dengan adanya sistem informasi penilaian kinerja karyawan di Bank Nagari Cab. Lubuk Alung bisa meminimalkan waktu menilai setiap karyawan, dan mendapatkan laporan yang di harapkan pemimpin di Bank Nagari Cab Lubuk Alung yang akurat, serta karyawan juga dapat melihat mereka sudah mempunyai nilai yang di harapkan perusahaan dengan adanya sistem informasi ini.

Kata kunci : sistem, informasi, penilaian kinerja, java

\section{PENDAHULUAN}

Perusahaan-perusahaan yang ada di Indonesia berusaha untuk meningkatkan sumber daya manusia yang ada. Dalam melaksanakan kegiatan, perusahaan sangat bergantung pada mesin, modal dan tenaga kerja. Tenaga kerja menjadi salah satu faktor dan aset yang memegang peranan penting dalam suatu perusahaan. Agar dapat bersaing dengan perusahaanperusahaan asing yang masuk ke Indonesia, perusahaan harus memperhatikan dengan cermat pengelolaan sumber daya manusia. Sumber daya manusia yang ada harus terlebih dahulu diolah dan dikembangkan sehingga dapat menjadi suatu potensi yang besar dan bermanfaat bagi perkembangan perusahaan khususnya dalam menciptakan sumber daya manusia yang terampil dan berkualitas.

Bank adalah suatu badan usaha yang bergerak di bidang keuangan atau jasa keuangan. Produk utama yang biasa dilayani berupa simpaan giro, tabungan maupun deposito. Bank juga digunakan sebagai tempat untuk simpan pinjam atau kredit bagi warga masyarakat yang membutuhkan dana pinjaman. Berdasarkan hal tersebut maka Bank akan selalu berhubungan erat dengan masyarakat. Untuk hal itu maka pelayanan menjadi penilaian suatu bank.

Salah satu praktek penilaian kinerja karyawan pada Bank Nagari Cab. Lubuk Alung sebagaimana yang telah terlaksana, mencerminkan kemampuan karyawan yang telah memahami apa yang menjadi tujuan, sasaran, dan harapan perusahaan. Selanjutnya muncul suatu persoalan pada saat dihadapkan pada prestasi kerja, yaitu model penilaian yang telah menjadi ketentuan perusahaan tidak dapat memenuhi tuntunan kondisi dan situasi di lingkungan usaha yang menyebabkan karyawan memiliki sikap dan perilaku yang dipaksakan untuk memenuhi peraturan perusahaan. 
Selama ini penilaian karyawan dilakukan secara manual menggunakan program aplikasi perkantoran. Masingmasing data diolah secara manual dan tidak terintegrasi, seperti absensi kehadiran, disiplin, kinerja, prilaku, prestasi dan pencapaian target karyawan.

Bank Nagari Cab. Lubuk Alung, performance appraisal report (hasil penilaian kinerja) yang telah disosialisasikan perlu adanya standarisasi dan ukuran penilaian yang tepat untuk menganalisis faktor-faktor yang mendukung ke arah penilaian yang objektif sehingga mewujudkan prestasi kerja yang memadai bagi tercapainya tujuan dan sasaran perusahaan.

Diharapkan dengan adanya sistem informasi penilaian kinerja karyawan di Bank Nagari Cab. Lubuk Alung bisa meminimalkan waktu dan menilai setiap karyawan, dan mendapatkan laporan yang diharapkan oleh Pemimpin di Bank Nagari Cab. Lubuk Alung yang akurat, serta karyawan juga dapat melihat apakah mereka sudah mempunyai nilai yang diharapkan perusahaan dengan adanya sistem informasi ini.

\section{TEMPAT PENELITIAN}

Penelitian dilakukan di Bank Nagari Cab. Lubuk Alung Pemilihan tempat dilakukan secara purposif (sengaja) dengan pertimbangan akan kelengkapan data dan informasi yang diperlukan untuk kegiatan penelitian mengenai aplikasi penilaian kinerja karyawan di Bank Nagari Cab. Lubuk Alung dengan menggunakan Java dan MySQL.

\section{DESAIN SISTEM}

\subsection{Desain Input}

Desain input merupakan tampilan pada layar monitor.

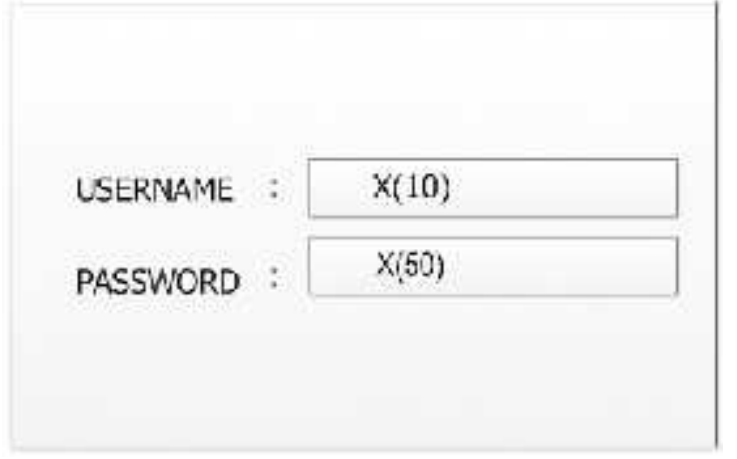

Gambar 1. Desain Input Login

\subsection{Desain Output}

Desain output merupakan tampilan (layout) saat menapilkan informasi yang dibutuhkan.

\begin{tabular}{|c|c|c|c|c|c|c|c|}
\hline a & памаз & musaus & and & 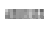 & war & minum & ina \\
\hline$m$ & $\boldsymbol{m}$ & 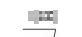 & 4 & 파 & 매 & 폐 & 叫 \\
\hline$m$ & (1) & In] & 피 & 펴 & 때 & 뎨 & 㖿 \\
\hline
\end{tabular}

Gambar 2. Desain output kandidat karyawan

\section{IV.IMPLEMENTASI SISTEM}

\subsection{Desain Database}

Mendesain database pada bab ini menggunakan XAMPP yang didalamnya terdapat PHP MyAdmin, yang dimulai dari menginstal Software tersebut serta mengikuti langkah-langkah dalam menginstal hingga selesai. Setelah proses instalasi selesai, aktifkan XAMPP dan mengaktifkan Apache dan MySql. Dilanjutkan dengan membuka browser Mozilla Firefox atau google crome, ketik phpmyadmin. maka kita akan masuk pada tampilan PHP MyAdmin 


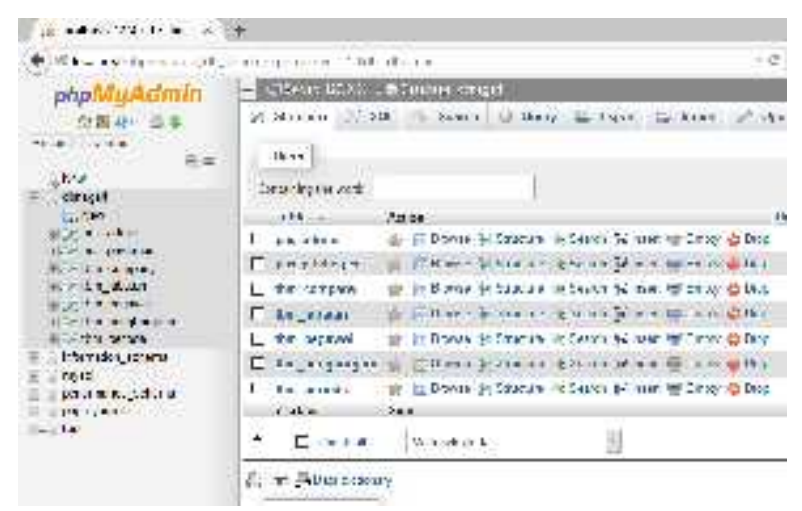

Gambar 3. Tabel Pada database

\subsection{Tampilan Login}

Pada Tampilan login ini, Admin Menginputkan username dan password untuk dapat masuk ke menu utama.

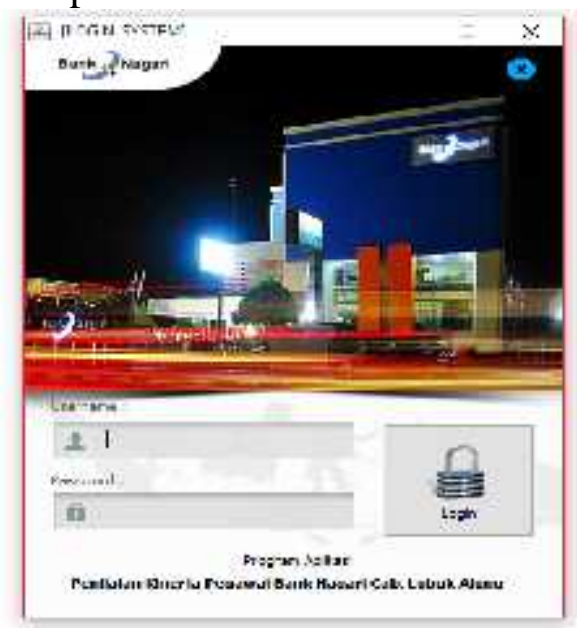

Gambar 4. Tampilan Login

Pada Tampilan login ini, Admin Menginputkan username dan password.

\subsection{Tampilan Menu List Kandidat}

Menu kandidat menampilkan data pegawai Bank Nagari Cabang Lubuk Alung.

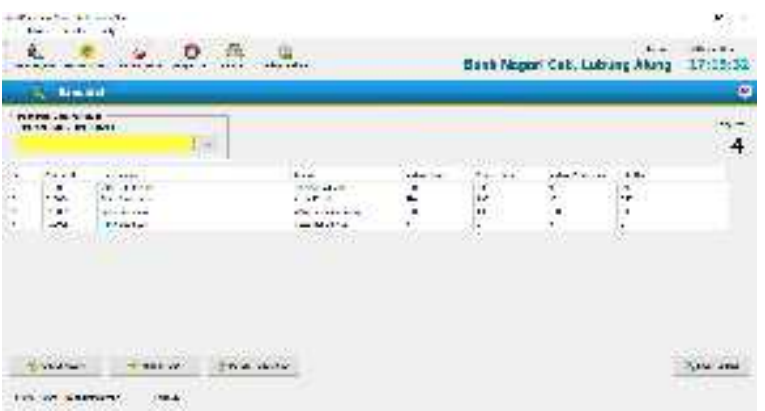

Gambar 5. Tampilan Menu List Kandidat

\subsection{Menu Laporan}

Menu laporan menampilkan kandidat dengan nilai tertinggi dan terendah.

\begin{tabular}{|c|c|c|c|c|}
\hline \multicolumn{5}{|c|}{ LAPORAN KANDIDAT } \\
\hline Maтapaganol & Aalaten Nbsersi & Pagtain-7anul & Fencharyas & Teal \\
\hline istiscustr & 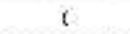 & 1 & 了 & 0 \\
\hline In toriti? & 13 & $M$ & $r$ & 290 \\
\hline teshresat & to & its & .) & 300 \\
\hline terioxth & 53 & III & $\because$ & 60 \\
\hline
\end{tabular}

Gambar 6. Menu Laporan

\section{KESIMPULAN DAN SARAN}

\subsection{Kesimpulan}

Berdasarkan hasil penelitian pada sistem informasi penilaian kinerja karyawan, maka penulis mengambil kesimpulan, sebagai berikut :

1. Sistem ini membantu pimpinan dalam memberikan informasi kinerja karyawan serta memberikan infromasi kandidiat terbaik sebagai informasi yang penting bagi pimpinan.

2. Memberikan pemahaman informasi dan pemahaman tetang kriteria penilaian karyawan.

\subsection{Saran}

Agar penerapan sistem penilaian kinerja karyawan inidapat terlaksana dengan baik maka ada beberapa hal yang sebaiknya perlu diperhatikan, yaitu :

1. Perlunya komputer server untuk peningkatan kinerja sistem dalam pengelolaan kinerja karyawan.

2. Perlunya pengembangan secara berkala tehadap perancangan sistemagar lebih baik lagi dalam penampilanya dan menu-menunya.

\section{DAFTAR PUSTAKA}

Burch, Jhon dan Gary Grudnitski. 1986. Information System Theory and Practice. New York: Jhon Wiley and Sons. 
Fathansyah, (1999). Basis Data. Bandung : Informatika.

Jogiyanto HM. (2005). Analisa \&Disain: Sistem Informasi Pendekatan Terstruktur Teori dan Praktek Aplikasi Bisnis. Yogyakarta: Andi Offset.

Kadir, Abdul. (2003). Pengenalan Sistem Infomasi. Yogyakarta : Andi Offset.

Nugroho, Adi. (2004). Konsep Pengembangan Sistem Basis Data. Bandung: Informatika.

Nugroho, Bunafit. (2005). Database Relasional dengan MySQL. Yogyakarta: Andi Offset.

Sutabri, Tata. (2012). Analisis Sistem Informasi. Yogyakarta: Andi Offset

Kusrini dan Koniyo, A. , 2007, Tuntunan Praktis Membangun Sistem Informasi dengan Visual Basic dan Microsoft SQL Server, Andi Offset, Yogyakarta.

Kadir, Abdul. (2009). Dasar Perancangan Dan Implementasi Database Relasional. Yogyakarta : Andi Offset 